\title{
New cause of death in young adults: Association between illicit drug abuse and amyotrophic lateral sclerosis
}

\author{
Azhari $\mathbf{A}^{1}$, Hasanabadi $\mathbf{H}^{2} *$, Rezaei $\mathbf{A}^{3}$ \\ ${ }^{1}$ Dr Amin Azhari, Assistant Professor, Department of Physical and Rehabilitation Medicine (PRM). ${ }^{2}$ Dr Hosein \\ Hasanabadi, Assistant Professor, Department of PRM., ${ }^{3}$ Dr Amir Rezaei Ardani, Department of Psychiatry. All are \\ affiliated with Faculty of medicine, Mashhad University of Medical Sciences, Mashhad, Iran
}

Address for Corresponding: Dr Hosein Hasanabadi, Email: hasanabadih@ mums.ac.ir

\begin{abstract}
Background: Neurodegenerative effects of illicit drugs have been proposed in many investigations. Amyotrophic lateral sclerosis is a fatal motor neuron disease characterized by degeneration of motor neurons, but the risk of amyotrophic lateral sclerosis among drug abusers is unknown. Methods: A nested case-control study was conducted in a teaching hospital to examine the association between drug abuse and amyotrophic lateral sclerosis. The study population included persons 18 to 40 years of age who were admitted in an electrodiagnostic medicine clinic for more than two year during the study period (January 2013 through April 2015) For each subject with ALS, 2 smoking-matched controls without ALS were randomly selected from the same population. Self-reported history of drug abuse was acceptable in both groups. Results: A total of 17 persons with ALS and 34 controls were identified, of whom 10 (58.8 percent) and 8 (23.5), respectively, had history of drug abuse. Persons with history of drug abuse had an increased risk of ALS (adjusted odds ratio, 2.6; 95 percent confidence interval, 1.2 to 5.7) as compared with controls. Conclusion: Drug abuse is an important risk factor for ALS, at least among young adults. The risk among drug abusers was at least or about double that among control group. The burden of mortality due to background ALS in drug abusers needs to be determined in future investigations.
\end{abstract}

Keywords: Substance Abuse, Amyotrophic Lateral Sclerosis, Risk Factor, Addiction, Drug Abuse.

\section{Background}

Amyotrophic lateral sclerosis (ALS) is a chronic fatal motor neuron disease, usually characterized by degeneration of both upper motor neuron (UMN) \& lower motor (LMN) neurons[1], so the patients experience combined UMN \& LMN signs and symptoms including weakness \& progressive muscular atrophy, swallowing problems which usually lead to respiratory failure and death in about 2-4 years[2]. Unfortunately, increasing incidence of ALS during recent years has been observed $[3,4]$.

On the other hand drug abuse is one of the most important health problems in many countries, including Iran[5, 6]. Despite the several side effects of drug abuse[7], it is believed that illicit drug abuse is increasing in developed countries [8]specially among the youth[9-11]; so clarification of possible outcomes of

Manuscript received: $26^{\text {th }}$ June 2015

Reviewed: $15^{\text {th }}$ July 2015

Author Corrected: $20^{\text {th }}$ July 2015

Accepted for Publication: $3^{\text {rd }}$ Aug 2015 addiction becomes more important.

Anyway several risk factors have been suggested for ALS $[8,12,13]$, but according to our knowledge the relationship between drug abuse \& amyotrophic lateral sclerosis is unknown. So we examined the association between drug abuse and ALS by conducting a nested case-control study in a teaching electrodiagnostic study (EDx) clinic.

\section{Methods}

This study has been performed in Emam Reza hospital, a referral teaching hospital in mashhad, Iran between January 2013 and April 2015.The study population was clients presented at EDx clinic for electrodiagnostic study. Young adult patients (18-40 years) with diagnosis of probable or definite ALS were enrolled in the case group of the study. Sporadic ALS is rare below 40 years[2], so to reduce confounding from age-related ALS, the upper age limit of 40 years was chosen. For 
each subject with diagnosis of definite or probable ALS, all eligible controls were assigned a random number, these numbers were then put into order, and the first 2 were selected as the controls. Controls were matched to case subjects according to gender \&cigarette smoking status. (pack year).

With the use El Escorial diagnostic criteria,subjects were defined as having definite ALS if they had UMN and LMN signs in the bulbar regions as well as at least two of three other spinal regions, while probable ALS was considered by the presence of UMN and LMN in at least two regions. Electrodiagnostic study was performed by an expert electromyographer. To assess whether or not the clients had history of drug abuse, a simple question was asked: "Have you ever had history of illicit drug dependency?. The reply options for this simple question was "Yes" or "No".

The main objective of the study was to examine the association between drug abuse and ALS mainly in young adults. SPSS software version 16 was used for statistical analyses. Differences with $\mathrm{P}$ value less than 0.05 were considered significant.

\section{Results}

Of a total of 154 of patients diagnosed as probable (or definite) ALS between January 2013 and April 2015,17 cases (11 percent) were determined in persons 18 to 40 years of age. Only 2 subjects (both of them were males with history of drug abuse) diagnosed as definite ALS and other 15 cases were considered as probable ALS [14]. For each case subject, 2 smoking-matched control subjects with the same gender (for a total of 34) were selected.

The mean smoking status \& female/male ratio both groups was 8.1 pack years and 0.3 respectively. There was no significant difference between two groups with regards of gender. The number of subjects with past medical history of at least one-time drug abuse was 10 (58.8 percent) and 8 (23.5 percent) in case \& control groups respectively. (Table 1$)$.

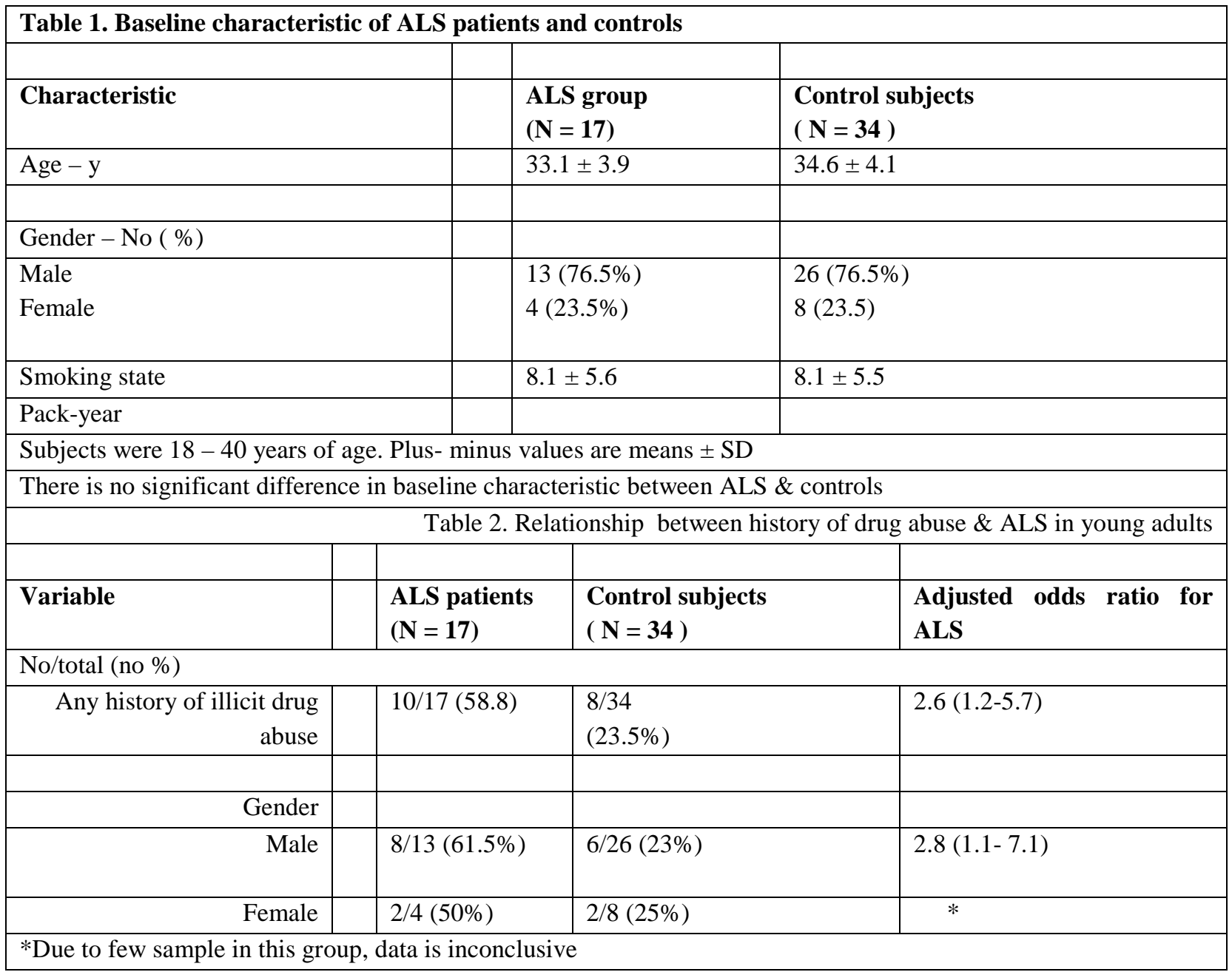


Illicit drug abuse is significantly increase risk of amyotrophic lateral sclerosis in young adults, in other word ALS should be considered as an important cause of death in addicted people.

Illicit drug abuse was determined significantly associated with an increase in risk of ALS in young adults (odds ratio, 2.6; 95 percent confidence interval, 1.2 to 5.7) (Table 2).

\section{Discussion}

A number of risk factors (modifiable or nonmodifiable) are proposed to be associated with ALS[12]. The two important genes are the SOD1 and the C9ORF72 genes, but there are also a number of other genetic contributors to ALS, although not to the same extent. These are important genes identified in familial ALS cases [15-19]. Besides genetic risk factors and family history of ALS, other established risk factors for the disease include male sex and older age[19]. Other risk factors can be placed into three categories: (1) Lifestyle risk factors including body mass index, physical fitness and physical exercise, intake of antioxidants and smoking (2) Occupational and environmental risk factors including electromagnetic fields, viral infection, metals and pesticides (3) other medical conditions, including cancer, head trauma, inflammatory and metabolic diseases[12]. The most important of them which could be a significant confounder for illicit drug abuse is smoking[21]; so we matched control group with respect to smoking status and of course gender.

This study found drug abuse as a new important risk factor for ALS in young adults. The mechanism by which illicit drugs cause ALS is not known. It has been speculated that the ALS is due to combined upper \& lower motor neurons degeneration and some mechanisms has been suggested [22]. On the other side, neurodegenerative effects of illicit drugs have been proven in many studies. Drug abuse is associated with increased risk for neurodegenerative disorders other than ALS including but not limited to Alzheimer, Parkinson \& Huntington diseases[23-27]. With combination of above data, we can hypothesize that illicit drugs may cause ALS by a toxic effect on the motor neurons.

If substance abuse can truly lead to ALS, a new cause for premature death among drug abusers will be uncovered. By involving respiratory muscles, patients with ALS, seems to be more susceptible to drug overdose which is considered as leading cause of death among illicit drug abusers [28, 29]. Undiagnosed possible background ALS among drug abusers is an important topic for future studies.
An important limitation of this study was few numbers of cases. It was absolutely predictable, because ALS is a rare disease in young adults. Our investigation has other limitations including limited number of case subjects, few cases with definite diagnosis, based on participant reports, without analyzing types of drug abuse, levels and timing of exposure. The possibility that participants may have underreported (or rarely over-reported) substance abuse cannot be excluded. Our data about more prominent types of drugs abuse by participants, levels and onset age of abuse was also inconclusive.

The association between drug abuse and ALS is unlikely to be confounded by several other risk factors. Perhaps the most lifestyle risk factor is smoking[20], but in our study case subjects and controls were matched with respect to smoking. It has been suggested that there is the inverse association between higher intake of antioxidants (such as vitamin E) and a lower risk of ALS. Some groups of drug dependents have nutritional deficiencies[30], but this effect in case subjects cannot be ruled out by this study. Finally, our study was observational research, so we were not allowed to ask for genetic laboratory data for the participants. It is also possible that common genetic factors, mentioned above, influence both propensity to drug abuse and ALS.

Future studies should analyze the relationship between young onset ALS and specific drugs, amount and the age of drug abuse onset. More research is needed to determine burden of subclinical or undiagnosed ALS among drug abusers and the impact of them on their survival.

\section{Conclusion}

Among young patients, addiction is an important risk factor for amyotrophic lateral sclerosis. ALS can be an important cause of mortality in patients with illicit drug dependency. However, further research is needed to clarify more important drugs which can lead to motor neuron diseases. The role of background ALS on 
premature mortality of drug abusers is also remains to be determined in future investigations.

\section{Abbreviations}

ALS: Amyotrophic Lateral Sclerosis

EDx: Electrodiagnostic study

LMN: Lower Motor Neuron

UMN: Upper Motor Neuron

Competing interests: The authors declare that they have no competing interests.

Authors' contributions: Amin Azhari participated in design of the study, performed statistical analysis and drafted the manuscript. Amir Rezaei Ardani Conceived of the investigation and participated in the design. Hosein Hasanabadi performed EDx of the participants and made the diagnosis of ALS.

Acknowledgements: We thank $\mathrm{Dr}$ Saeed Eslami Hasanabad who provided insight and expertise that greatly assisted the research.

\section{Funding: Nil \\ Conflict of interest: Nil \\ Permission from IRB: Yes}

\section{References}

1. Mitchell JD, Borasio GD: Amyotrophic lateral sclerosis. Lancet 2007, 369(9578):2031-2041.

2. Kiernan MC, Vucic S, Cheah BC, Turner MR, Eisen A, Hardiman O, Burrell JR, Zoing MC: Amyotrophic lateral sclerosis. Lancet 2011, 377(9769):942-55.

3. Doi Y, Atsuta N, Sobue G, Morita M, Nakano I: Prevalence and incidence of amyotrophic lateral sclerosis in Japan. Journal of epidemiology / Japan Epidemiological Association 2014, 24(6):494-9.

4. Mehta P, Antao V, Kaye W, Sanchez M, Williamson D, Bryan L, Muravov O, Horton K: Prevalence of amyotrophic lateral sclerosis - United States, 20102011. Morbidity and mortality weekly report Surveillance summaries (Washington, DC : 2002) 2014, 63 Suppl 7:1-14.
5. Nessa A, Latif SA, Siddiqui NI, Hussain MA, Hossain MA: Drug abuse and addiction. Mymensingh medical journal : MMJ 2008, 17(2):227-35.

6. Naserbakht M, Djalalinia S, Tayefi B, Gholami M, Eftekhar Ardabili M, Shariat SV, Taban M, Hajebi A, Behtaj F, Sajadi SA et al: National and sub-national prevalence, trend, and burden of mental disorders and substance abuse in Iran: 1990 - 2013, study protocol. Archives of Iranian medicine 2014, 17(3):182-8.

7. Boddiger D: Drug abuse in older US adults worries experts. Lancet 2008, 372(9650):1622.

8. Malek AM, Barchowsky A, Bowser R, HeimanPatterson T, Lacomis D, Rana S, Youk A, Stickler D, Lackland DT, Talbott EO: Environmental and occupational risk factors for amyotrophic lateral sclerosis: a case-control study. Neuro-degenerative diseases 2014, 14(1):31-8.

9. Pradhan BK, Cagande CC, Pumariega AJ: Substance abuse among culturally diverse youth. Adolescent medicine: state of the art reviews 2014, 25(1):172-83.

10. Mesic S, Ramadani S, Zunic L, Skopljak A, Pasagic A, Masic I: Frequency of substance abuse among adolescents. Materia socio-medica 2013, 25(4):265-9.

11. Jalilian F, Karami Matin B, Ahmadpanah M, Ataee M, Ahmadi Jouybari T, Eslami AA, Mirzaei Alavijeh M: Socio-demographic characteristics associated with cigarettes smoking, drug abuse and alcohol drinking among male medical university students in Iran. Journal of research in health sciences 2015, 15(1):42-6.

12. Ingre C, Roos PM, Piehl F, Kamel F, Fang F: Risk factors for amyotrophic lateral sclerosis. Clinical epidemiology 2015, 7:181-93.

13. Das K, Nag C, Ghosh M: Familial, environmental, and occupational risk factors in development of amyotrophic lateral sclerosis. North American journal of medical sciences 2012, 4(8):350-355.

14. World Federation of Neurology Research Group on Neuromuscular Disease.El Escorial World Federation of Neurology Criteria for diagnosis of amyotrophic lateral sclerosis.J NeurolSci 1994; 124(suppl):96-107 
15. Maruyama H, Morino H, Ito H, Izumi Y, Kato H, Watanabe Y, Kinoshita Y, Kamada M, Nodera H, Suzuki H et al: Mutations of optineurin in amyotrophic lateral sclerosis. Nature 2010, 465(7295):223-226.

16. Rosen DR: Mutations in $\mathrm{Cu} / \mathrm{Zn}$ superoxide dismutase gene are associated with familial amyotrophic lateral sclerosis. Nature 1993, 364(6435):362.

17. Wu CH, Fallini C, Ticozzi N, Keagle PJ, Sapp PC, Piotrowska K, Lowe P, Koppers M, McKenna-Yasek $\mathrm{D}$, Baron DM et al: Mutations in the profilin 1 gene cause familial amyotrophic lateral sclerosis. Nature 2012, 488(7412):499-503.

18. Vucic S, Nicholson GA, Chio A, Kiernan MC: Apparent anticipation in SOD1 familial amyotrophic lateral sclerosis. Amyotrophic lateral sclerosis \& frontotemporal degeneration 2013, 14(5-6):452-456.

19. Van Blitterswijk M, van Es MA, Koppers M, van Rheenen W, Medic J, Schelhaas HJ, van der Kooi AJ, de Visser M, Veldink JH, van den Berg LH: VAPB and C9orf72 mutations in 1 familial amyotrophic lateral sclerosis patient. Neurobiology of aging 2012, 33(12):2950 e2951-2954.

20. Armon C: An evidence-based medicine approach to the evaluation of the role of exogenous risk factors in sporadic amyotrophic lateral sclerosis. Neuroepidemiology 2003, 22(4):217-28.

21. Armon C: Smoking may be considered an established risk factor for sporadic ALS. Neurology 2009, 73(20):1693-1698.

22. Shaw PJ: Mechanisms of cell death and treatment prospects in motor neuron disease. Hong Kong medical journal = Xianggang yi xue za zhi / Hong Kong Academy of Medicine 2001, 7(3):267-280.
23. Rodriguez MJ, Pugliese M, Mahy N: Drug abuse, brain calcification and glutamate-induced neurodegeneration. Current drug abuse reviews 2009, 2(1):99-112.

24. Gramage E, Herradon G: Connecting Parkinson's disease and drug addiction: common players reveal unexpected disease connections and novel therapeutic approaches. Current pharmaceutical design 2011, 17(5):449-461.

25. Chin TS: History of substance abuse and risk of extrapyramidal side effects. Psychiatry (Edgmont (Pa : Township)) 2006, 3(6):18.

26. Byars JA, Beglinger LJ, Moser DJ, GonzalezAlegre P, Nopoulos P: Substance abuse may be a risk factor for earlier onset of Huntington disease. Journal of neurology 2012, 259(9):1824-1831.

27. Roussotte FF, Daianu M, Jahanshad N, Leonardo CD, Thompson PM: Neuroimaging and genetic risk for Alzheimer's disease and addiction-related degenerative brain disorders. Brain imaging and behavior 2014, 8(2):217-33.

28. Rivara FP, Mueller BA, Somes G, Mendoza CT, Rushforth NB, Kellermann AL: Alcohol and illicit drug abuse and the risk of violent death in the home. Jama 1997, 278(7):569-75.

29. Nyhlen A, Fridell M, Hesse M, Krantz P: Causes of premature mortality in Swedish drug abusers: a prospective longitudinal study 1970-2006. Journal of forensic and legal medicine 2011, 18(2):66-72.

30. Nabipour S, Ayu Said M, Hussain Habil M: Burden and nutritional deficiencies in opiate addictionsystematic review article. Iranian journal of public health 2014, 43(8):1022-1032.

\section{How to cite this article?}

Azhari A, Hasanabadi H, Rezaei A. New cause of death in young adults: Association between illicit drug abuse and amyotrophic lateral sclerosis. Int J Med Res Rev 2015;3(7):721-725. doi: 10.17511/ijmrr.2015.i7.136. 